\title{
Acoustic analysis of selected sacred buildings in Szczecin
}

\author{
Agata Stolarska ${ }^{1}$, Jarosław Strzałkowski ${ }^{2}$, Agata Kandybowicz ${ }^{3}$
}

\author{
${ }^{1}$ Department of Building Physics and Building Materials; Faculty of Civil and Environmental \\ Engineering; West Pomeranian University of Technology; 50 Piastów Av., 70-311 Szczecin, Poland; \\ siwinska@zut.edu.pl (D) 0000-0003-1923-2920 \\ ${ }^{2}$ Department of Building Physics and Building Materials; Faculty of Civil and Environmental \\ Engineering; West Pomeranian University of Technology; 50 Piastów Av., 70-311 Szczecin, Poland; \\ jaroslaw.strzalkowski@zut.edu.pl iD 0000-0001-7001-9303 \\ ${ }^{3}$ Department of Building Physics and Building Materials; Faculty of Civil and Environmental \\ Engineering; West Pomeranian University of Technology; 50 Piastów Av., 70-311 Szczecin, Poland; \\ agata.kandybowicz@gmail.com
}

\begin{abstract}
The aim of this study was to acoustically assess selected sacred buildings located in Szczecin. The research part contains the research methodology and the results obtained. The research was carried out using two methods. The first one is the integrated impulse response method where, using a bursting balloon, the time of sound pressure drop was measured at selected points of the object. In the second research method, the interrupted noise method, the sound pressure drop was measured after the noise generated by the omnidirectional loudspeaker had ceased. Reverberation time was calculated for the results obtained, which is the main and basic parameter determining the interior acoustics. On the basis of the above-mentioned measurements, the reverberation indicators for the temples were also calculated. When analysing the components of the reverberation indicator, it was noticed that poor acoustics in the sanctuary concerns speech, while interior acoustics is good for the reception of organ music. In the analysed church, the reception of liturgical music is also better than the reception of speech, but the differences between these values are small.
\end{abstract}

Keywords: acoustics, sacred buildings, reverberation time, sound pressure

\section{Introduction}

The acoustic profile of a room depends primarily on its shape and the absorbing materials used, as well as the arrangement of sound-reflecting materials. The acoustic field in a room consists of the waves that run directly from the source of sound and the waves which overlap each other once or repeatedly.

When designing spaces with their sound quality in mind, attention is paid to the relationship between specular and diffused reflection. Fully diffused reflection is desirable as it covers 
a wide range of sound frequencies; however, partial diffusion occurs more often. In practice, the propagation of sounds in an enclosed space is influenced by its shape. The mutual location of the walls and ceilings can differentiate the directions of reflected waves that reach the audience. In order to improve the propagation of sound in geometrically simple interiors, acoustic structures or systems are also used, with a defined number of cavities; the task is to disperse a wide range of sound frequencies, depending on the size of the blocks used to produce it. It is one of the many types of distractor in the group of sound diffusing acoustic systems. It was invented by the German acoustician Manfred R. Schroeder [1]. The significance of acoustics is closely related to sacred buildings. The builders of the first churches used the principles of sound propagation in order to make sure that the acoustics of the interior is good enough for the music accompanying the liturgy to sound properly and the speech to be clearly heard by the congregation. This approach can be observed in a multitude of temples all over the world. They largely differ in terms of the external appearance, form, interior fittings, ornaments and building materials. The arrangement of the interior of the temple has great impact on its acoustics. When it comes to acoustics, the interior of the building is more important aspect than its external shape. With this in mind, the authors [2] categorized churches according to the shape of their interior. In large buildings with geometric shapes and simple décor, the effect of reverberation is observed. In buildings with more elaborate geometry, with aisles, chapels or a series of columns, the acoustics is much better due to the fact that these elements reduce reverberation and improve sound transmission. However, the more complicated the layout of the interior, the more difficult it is to predict the acoustic phenomena occurring inside and take them into account when designing a church [2]. The authors of a previous study have pointed out that the great variety of temple shapes is one of the most unsteady factors when comparing both their acoustics and measurements of different assemblies at the same site [3]. A comparative analysis of the acoustics of sacred buildings from different eras, based on experimental research by scientists on the acoustic qualities of churches from around the world, was described in the article [4].

Engel and colleagues, based on many years of research, have defined the conclusions regarding the field of acoustics in sacred buildings [2]. The findings show that unfavourable acoustic phenomena occur in spaces with oval and round bases and in interiors with domes. This is because the concentration of sound waves occur in one or more spots. Standing waves are generated in buildings with a rectangular or square plan, which causes local amplification or weakening of the acoustic signal. The most complex in terms of architecture and acoustics are composite interiors with side chapels, naves and recesses because when designing them, the theory of coupled rooms must be taken into account.

Carbonari and colleagues have proposed a set of guidelines for the selection of the location of sound sources and receivers and suggests appropriate equipment combinations for acoustic measurements in churches [5]. Measurements of reverberation time at various locations of sound sources and receivers done as part of a large survey of Roman Catholic churches in Portugal have been investigated previously [6], [7]. In the article [7], they presented the acoustic qualities of the interior of the Basilica of the Holy Trinity in Fatima, designed for 9,000 people. The reverberation time was also tested. On the other hand, the work [8] contains the results of measurements of the real reverberation time in the $125-8000 \mathrm{~Hz}$ band, made in the Dominican Order church in Krakow. Detailed analyses and comparison of the reverberation time as a function of frequency in Orthodox churches in Poland have been carried out previously in [9]. The recent article [10] discusses the acoustic problems in a contemporary Catholic church in Poznan and presents a study of the impact of the ceiling structure on its acoustics. 
The paper [11] reported two examples of sacred buildings in Italy (S. Dominic, Imola) and the acoustic design specifically developed for using these spaces as concert halls. The topic of using the church as a temporary auditorium is also presented in [12]many of the ancient buildings, especially sacred architecture, are subject to renovation projects by converting their initial occupation type for temporary exposition. In particular, the demand for assisting to live musical performance is increased considerably in Italy because of the missing of places dedicated to the performing arts. As such, one of the churches of Imola (i.e. San Domenico.

Many methods can be used to assess the interior acoustics based on various measurement parameters. The basic and most important parameter is the reverberation time $\mathrm{T}$. There are many indirect and direct methods to measure reverberation time in a space. The standard [13] describes the measurement procedures, irregularities, the scope of reports for the interrupted noise and impulse response methods. It also specifies the requirements for the equipment to be used for the correct performance of such measurements. The methods mentioned above have been used in this work. Measurements of acoustic parameters in Spanish churches according to [13] standard was presented in the work [14].

Bearing in mind the above information, the objective of the current study was to examine the acoustic measurements in two religious buildings located in Szczecin and to evaluate them in terms of sound quality. This study was carried out using two methods; integrated impulse response and interrupted noise methods. Based on the obtained results, reverberation time was calculated, which is the main and basic parameter determining the acoustics of the interior.

\section{Materials and methods}

\subsection{Description of the analysed buildings}

Two acoustics properties of two type of sacred buildings, the church and the sanctuary, located in Poland in Szczecin at Rydla Street was analysed.

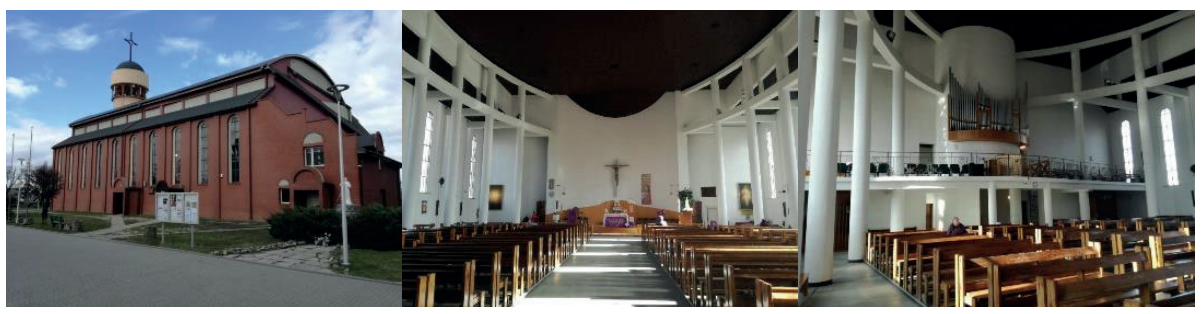

Fig. 1. Church at the parish of the Immaculate Heart of the Blessed Virgin Mary in Szczecin. Source: own study [15]

The church was built on a rectangular plan (Fig. 1). It is a single-storey reinforced concrete structure building without a basement. The structure is supported by reinforced concrete pillars elliptically arranged inside. On both sides of the church, there are lower aisles behind the pillars. Thanks to the large span between the pillars, the aisles form an integral part of the nave. The entrances to the church are: the main entrance portal with double brass doors, and 3 side entrances with wooden doors. Above the porch there is a gallery for the choir and the organist. From the level of the gallery there is a spiral staircase leading to the belfry topped with a dome. The interior of the church is unfinished. In the presbytery the walls and the floor 
are made of wooden boards. In other parts of the church, there is only a concrete screed on the floor. In the center of the presbytery there is a wooden altar and two pulpits made of solid bricks with wooden stands. In the main nave there are 4 rows of wooden benches on a wooden landing. In the aisles there are benches parallel to the wall. The volume of the building is $12258.5 \mathrm{~m}^{3}$ and the floor usable area is $997.5 \mathrm{~m}^{2}$. Based on the volume of the building, it was classified as a mid-sized church with a volume between 1500 and $15000 \mathrm{~m}^{3}$. The geometry of the church was classified as a complex multi-body (multi-block) non-dome sacred object.
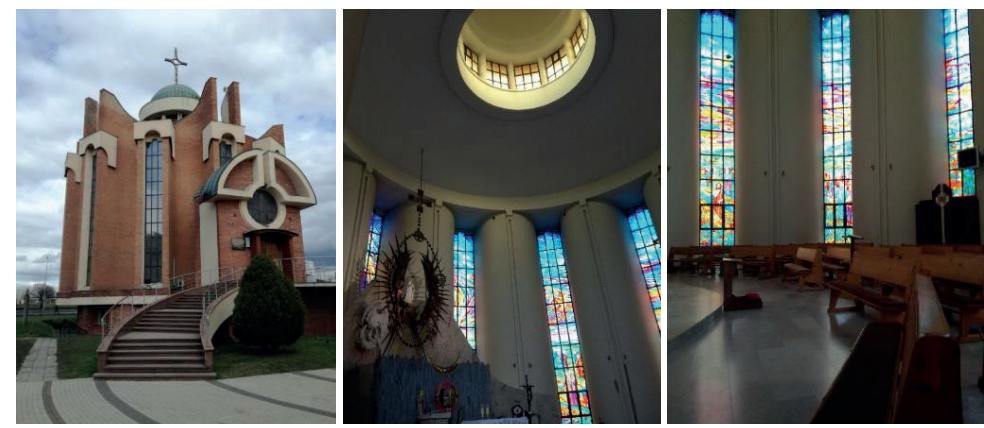

Fig. 2. Chapel of the Immaculate Heart of the Blessed Virgin Mary in Szczecin. Source: own study [15]

The sanctuary (Fig. 2) is a two-storey brick structure, without a basement, it has a shape of a twelve-sided polygon circumscribed to the circle. Its first floor is a lowered ground floor. The upper storey is elevated above the ground and it forms the main nave of the sanctuary. There is an organ gallery in the chapel that can be accessed by reinforced concrete stairs. There are two pairs of stairs circumscribed to the circle, leading to the interior of the sanctuary. The skeletal structure of the building, consisting of columns fastened with binders and wreaths, is made of reinforced concrete, and the walls are made of solid brick. The inter-storey ceiling is made as a reinforced concrete slab. The skeletal frame is crowned with a reinforced concrete dome. The interior of the sanctuary is simple and there are not many sculptures or ornaments. There is a marble altar and a pulpit in the presbytery, as well as a lectern and seats for the members of the liturgical service. The tabernacle is surrounded by a stone wall. In the main part of the building, there are wooden benches with fabric cushions on the seats for the congregation. The chapel is a contemporary structure with a volume of $4681.5 \mathrm{~m}^{3}$, and therefore it can be classified as a mid-size church, even though its volume is almost three times smaller than that of the church described previously. The geometry of the block is complex, varied, single-dome. Despite the fact that both analysed buildings have been classified as sacred objects of complex geometry, the form of the chapel is more problematic due to its dome and rounding of the external walls. The interior of the chapel is finished but does not abound with decorative elements.

\subsection{Measurement methods}

The reverberation time tests were performed in accordance with [13] standard. First, the measurement of the impulse response was done. To generate the required sound pressure, inflated balloons up to a diameter of about $18 \mathrm{~cm}$ were burst, which caused a total sound level of approx. $92 \mathrm{~dB}$ (filter A). The acoustic tests in the church were preceded by the 
charting out a grid of measuring points with dimensions of 4.0 by $4.5 \mathrm{~m}$ in the main nave of the church (Fig. 3).

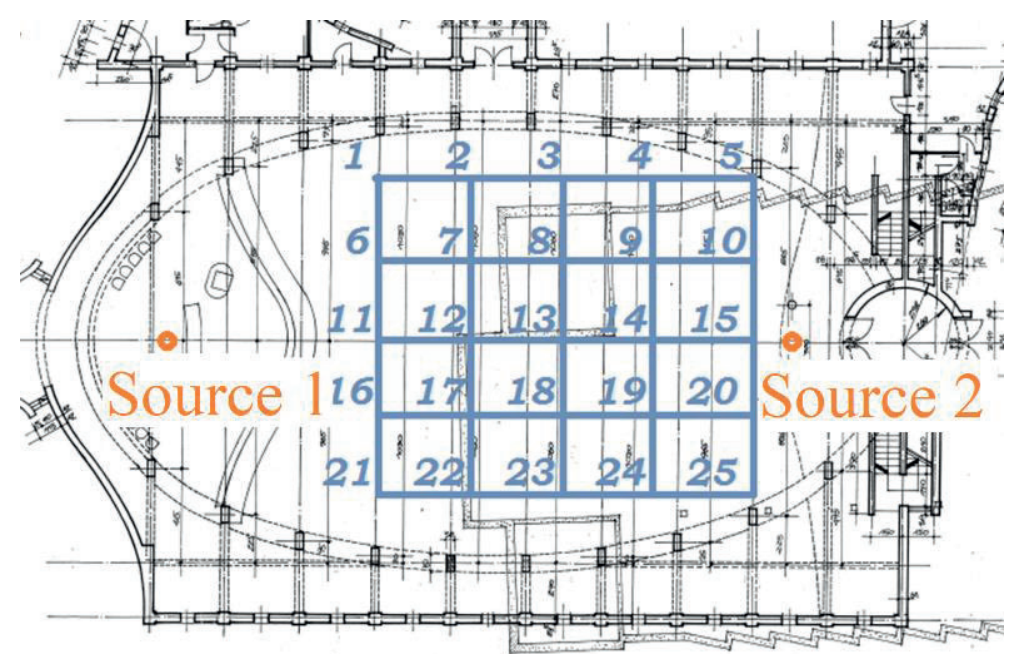

Fig. 3. The church plan with a sketched measurement grid and the location of sources no. 1 and no. 2 . Source: own study

The selected points were located between the benches for the congregation to recreate the auditory impression for the audience during the mass. The location of source 1 was based on the nature of the structure, as the most important point during the liturgy and as the main place from which the sound is emitted. A similar approach to the selection of the sound source location has been presented in the article [16]. The impulse reactions were determined for the following locations of the sound source: the main altar, the pulpit, the choir and the organ, which correspond to the places where liturgical, musical and cultural activities take place in the temple under study. Source 2 was located in the central part of the choir, next to the organ. The choir is the second, after the presbytery, the most important place from which sound is directed to the faithful. It is mainly singing and, in most cases, organ music. At these sound source locations, the balloons were burst. Each of them was burst at a height of approx. $1.2 \mathrm{~m}$ above the ground. The other person recorded the impulse response of the exploding balloon. Each measurement was performed in the direction of the presbytery and at the height of approx. $1.2 \mathrm{~m}$.

The balloon was burst each time after approx. 5 seconds from activation of the sound level meter. The purpose of this procedure was to record the background noise level at a given point of the temple before the balloon explosion. The measurement itself was long enough to register the pressure drop to the value indicated on the screen at the beginning of the test. The same steps were performed for the sound source 2, which was situated in the central part of the gallery, next to the organ.

After the measurements in the church using the impulse response method were done, acoustic analysis was performed using the interrupted noise method. The spherical loudspeaker was placed on the floor, at the location of the sound source 1. Before turning the loudspeaker on, the sound intensity of the exploding balloon was measured at a distance of $1 \mathrm{~m}$ from the 
sound source 1 . The intensity level of approx. $80 \mathrm{~dB}$ was noted on the sound level meter. This measurement was used to set the same noise level generated by the loudspeaker. The interrupted noise test was performed using pink noise. As in the first method, measurements were made at a height of about $1.2 \mathrm{~m}$ at grid points. Before the sound generator was turned on, background noise had been measured for about 5 seconds, and then the loudspeaker was activated at the previously set sound intensity values for approx. 5 seconds. This time allowed the temple to be fully filled with the given noise, which was evidenced by the constant reading of the meter. About 5 seconds after activating the loudspeaker, the noise was turned off and the acoustic drop at a given measuring point was measured. The total measurement time at one point was 20 seconds.

Acoustic measurements in the sanctuary were performed in accordance with the previously described rules. Due to the specific shape of the chapel, the grid of measurement points was arranged in a different way. In this case, the measuring points are situated in an arc, among the benches. 16 measurement points were provided for sound source 1 , and the $17^{\text {th }}$ point was sound source 1 itself. 16 measurements were performed for sources 2 and 3, except that the last measuring point was in the presbytery. The arrangement of measuring points in the chapel is shown in the Fig. 4.

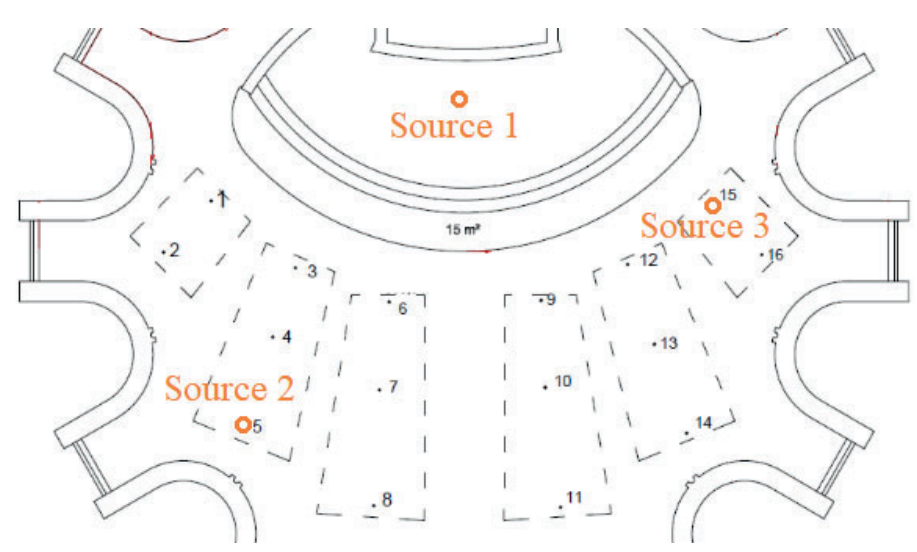

Fig. 4. Chapel plan with sketched location of measurements and locations of sources. Source: own study

The tests in the chapel were performed using both the interrupted noise method and the impulse response method. Measurements for both methods were made at a height of about $1.2 \mathrm{~m}$ above the floor, and each time in the direction of the presbytery. Due to the nature of the location, source 1 was located in the presbytery behind the altar, while other sound sources were positioned among the benches for the congregation. This approach resulted from the acoustic reception of sounds in the chapel during the liturgy and the most resounding voices of other members of congregation in selected points.

\section{Results}

\subsection{Measuring devices}

Two methods were used: the interrupted noise method, in which an omnidirectional loudspeaker was used as an impulse generator, and the integrated impulse response method, 
for which the increase in the sound pressure level was caused by a balloon explosion. Balloon explosion as a source of sound is used, among others, in works [17]. To measure the reverberation time in the room, it was necessary to use an omnidirectional sound source and a sound meter. The sound level meter SVAN 979 and DL 203 spherical loudspeaker were used to perform the tests.

In the studied temples, the places with the sound source were designated (in the church -2 spots, in the chapel -3 spots) and measurements were made using both methods in each location of the source. Each measurement was performed for 7 frequencies ranging from $125 \mathrm{~Hz}$ to $8000 \mathrm{~Hz}$, and for overall level with a correction filter A - Total A. In total, 1568 charts were obtained illustrating the sound pressure drop in the tested point for a given frequency. Due to the huge number of results, only selected points will be described in detail and global statements for both structures will be presented.

\subsection{Church results}

The first analysed subject is the comparison of the results obtained for both methods. The point 13 will be interpreted as the central point of the grid for source 1. The charts (Fig. 5) present the obtained values of the sound pressure level with the specification of individual frequencies.

(a)

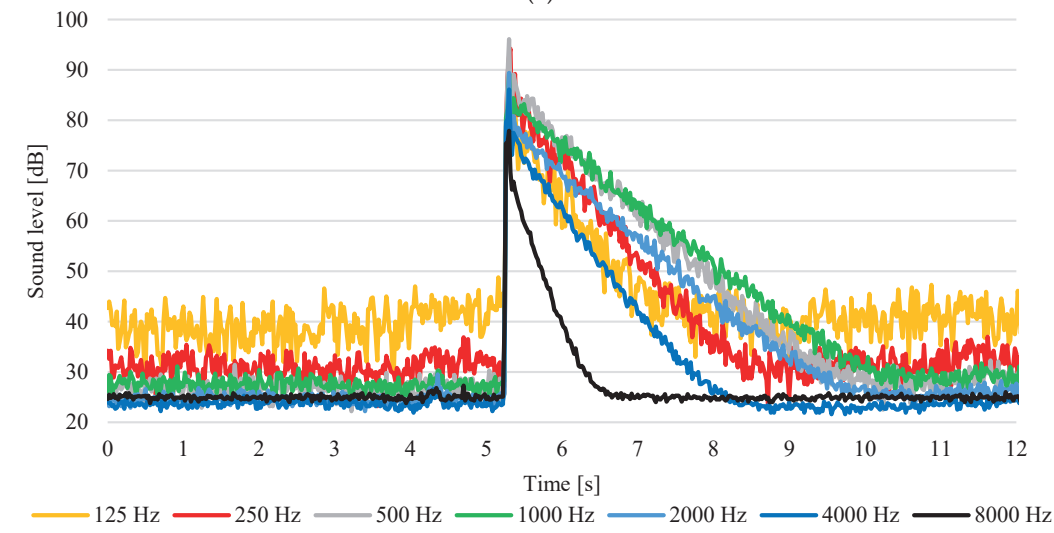

(b)

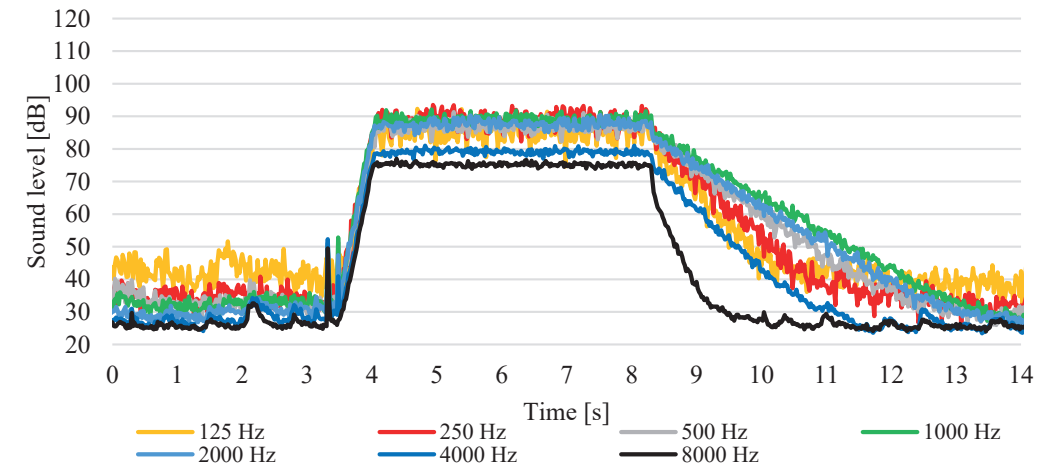

Fig. 5. The graphs of sound levels using the pulse method (a) and interrupted noise method (b) 
Both charts clearly show the background noise recorded in the first few seconds of the measurement. The acoustic background is at essentially the same levels, and slight discrepancies may result from a temporary change in the conditions inside the tested space or from the acoustic influence coming from the outside. The chart (a) clearly shows the moment of balloon explosion corresponding to an instantaneous spike in the sound pressure level. The chart (b) shows a gradual increase in the sound pressure level of the sound generated by the omnidirectional loudspeaker so that the maximum value is reached with a slight time shift. This difference results from the sound impulse generator used and the speed of the generated sound in the air. In both cases, the nature of the decrease in the sound pressure level over time is similar, which proves that the results are analogous and that the two methods used are equivalent. The descending trend of the chart is recorded until the pressure level value for the background noise is reached, of the value equal to the measurement before the sound impulse. The range of the drop in sound pressure level is the key section of the chart for the reverberation time study. Its slope is different for each frequency. The steepest pressure drop was recorded at $8,000 \mathrm{~Hz}$. This is equivalent to the greatest slope of the line fitted to this chart. The smallest decrease was recorded for $1000 \mathrm{~Hz}$.

Figure 6 shows an example of a drop in sound pressure for the frequency of $1000 \mathrm{~Hz}$ for the source 1 . To compare the results with the interrupted noise method, the chart for the same grid point 12 in the loudspeaker test is presented.

(a)

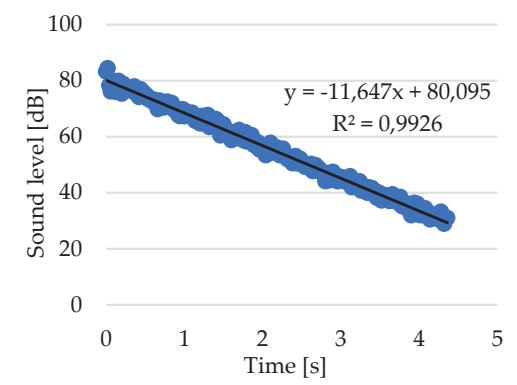

(b)

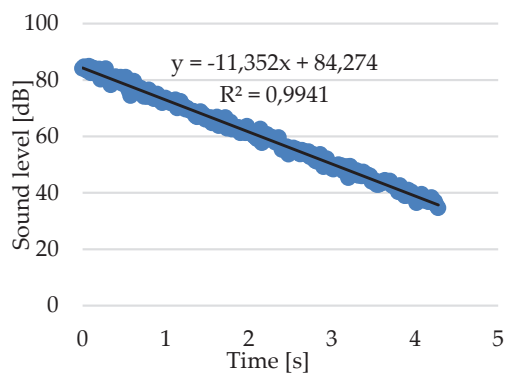

Fig. 6. The graphs of the decrease in sound pressure levels for the frequency of $1000 \mathrm{~Hz}$ obtained by the impulse method (a) and interrupted noise method (b)

The coefficient of determination for the balloon is $\mathrm{R}^{2}=0.993$, and for the loudspeaker, $\mathrm{R}^{2}=0.994$. The obtained high values of the $\mathrm{R}^{2}$ coefficient indicate a good fit of the data to the linear function. The trend line is very well adjusted to the results obtained. It is clearly noticeable that the nature of both charts is similar, as evidenced by the maximum and minimum sound pressure level for each chart, the range of arguments of the function, and, above all, the slope of the downward curve.

The obtained reverberation time values for all variants oscillate between $5.1-5.4$ seconds for each examined point of the temple, which is a difference of approx. 5.6\%. This proves an even acoustic distribution in the church. It has also been shown that the location of the sound source in the presbytery or in the gallery does not affect the acoustic perception of sound.

The obtained results of the reverberation time can also be used to create a relationship presenting the characteristics of the tested building and to describe the method of changing 
the reverberation time for individual measurement points in frequency bands. The chart in Fig. 7 shows the dependence of the reverberation time on frequency, where the individual points of the church measurement grid were marked with different colours.

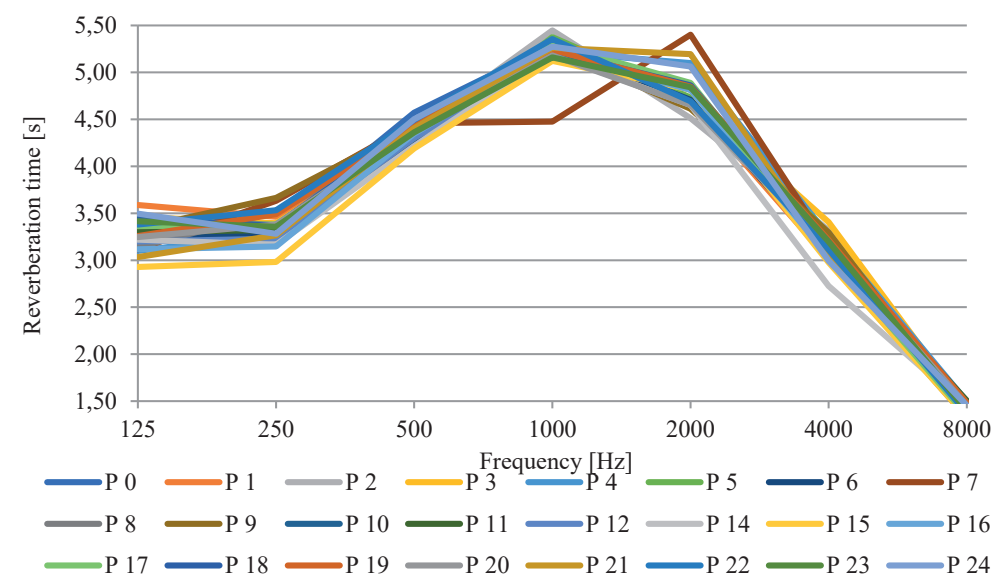

Fig. 7. Reverberation time at various measuring points obtained by the impulse response method obtained for sound no 1 in Church

Because the temple is still unfinished, it was expected that the reverberation time at the low bands would give higher values. The low value of the reverberation time for higher frequencies results from high air absorption, while in the case of lower frequencies, it is the result of the presence of sound-absorbing objects in the space. Despite the fact that the church is uncompleted, the presbytery is panelled, and under the benches for the congregation, wooden boards are laid. These structures are most likely responsible for reducing the reverberation time in the temple. By comparing the reverberation times of the given frequencies at individual points (by the impulse response method), a chart illustrating the frequency bands for the building is obtained (Fig. 8). Lower values of the reverberation time for the frequencies of 125, 250 and $500 \mathrm{~Hz}$ were obtained by the researchers in church in Fatima [7].

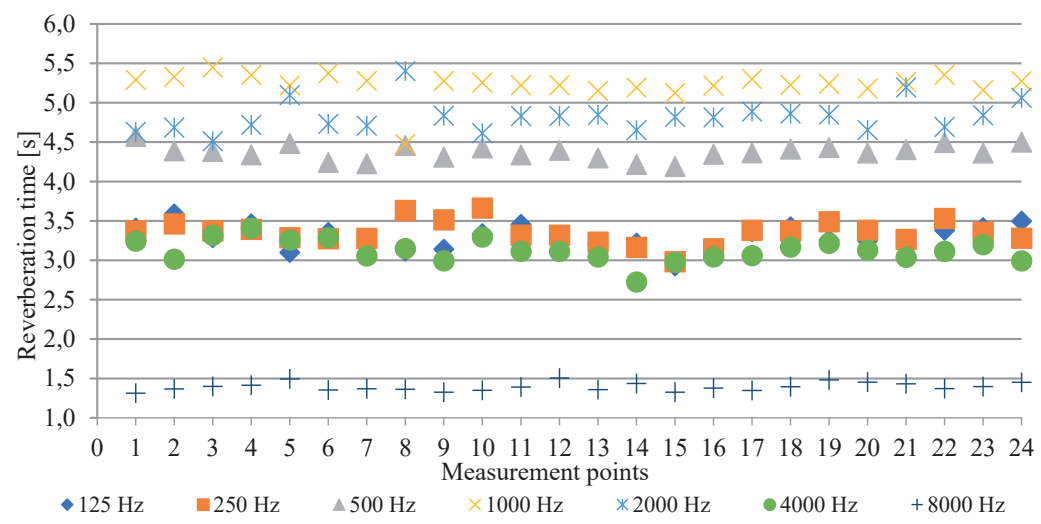

Fig. 8. Reverberation time diagram in individual frequency bands at various measuring points 
The absorption on the surface of the partitions also had an influence on the obtained reverberation times in accordance with the Sabine equation. Despite the unfinished condition of the church, its interior features well-absorbing elements such as pews, platforms and panelling. The interior of the church was not finished on the day of the examination. In the presbytery, only the wall cladding is $2.5-1.5 \mathrm{~m}$ high and the floor is made of wooden boards.

Due to the diversity of sacred buildings, there are no specific standard values for the reverberation time. In order to ascertain whether the acoustics of the examined churches is good, the obtained times were compared with the results of other churches described in the literature. Engel et al. have examined a number of places of worship in terms of various acoustic parameters [2]. One of the measured parameters was the reverberation time. The acoustics of the structures analysed in the publication are varied. Churches with large volume are characterized by long reverberation times, and thus, their acoustics is good for the performance of organ music but not so good for transmission and reception of speech. These phenomena can be observed, for example, in Saint Peter's Basilica in Rome. Among the mid-sized buildings, there are churches with poor acoustics - e.g. Charles' Church in Tallinn, whose interior is covered with flat, sound-reflecting surfaces - and buildings with good acoustics, such as St Mark's Church in Munich. This fact demonstrates is that the volume of the temple is not the only criterion for acoustic analysis, but the shape and finishing of the building determine the acoustics of a given interior as well. The authors describe St. Thomas Church in Leipzig as a structure with good interior acoustics. However, the lower reverberation times for the 125 and $250 \mathrm{~Hz}$ bands, resulting from wooden finishing of walls are an unfavourable phenomenon. Although lower frequency sounds are less audible, the room acoustics is good. The volume of the church examined in this study is $12258.75 \mathrm{~m}^{3}$ and it is slightly smaller than the volume of St Thomas Church in Leipzig. The nature of these two objects is similar, but for the church in Szczecin, the tested reverberation time values are approx. 1 second longer. As it was already mentioned, the lower value of the reverberation time at low frequencies results from the finishing of the walls and wooden panelling. Both objects are similar in terms of the surface and the absorbing structures used, but the higher value of the reverberation time combined with a smaller volume of the church in Szczecin proves its worse acoustic conditions.

\subsection{Sanctuary results}

As it was in the case of the church, also for the sanctuary, the research methods used were compared first. In order to present a picture of the obtained values for the sanctuary, the representative point 8 was described and showed in Fig. 9. 
(a)

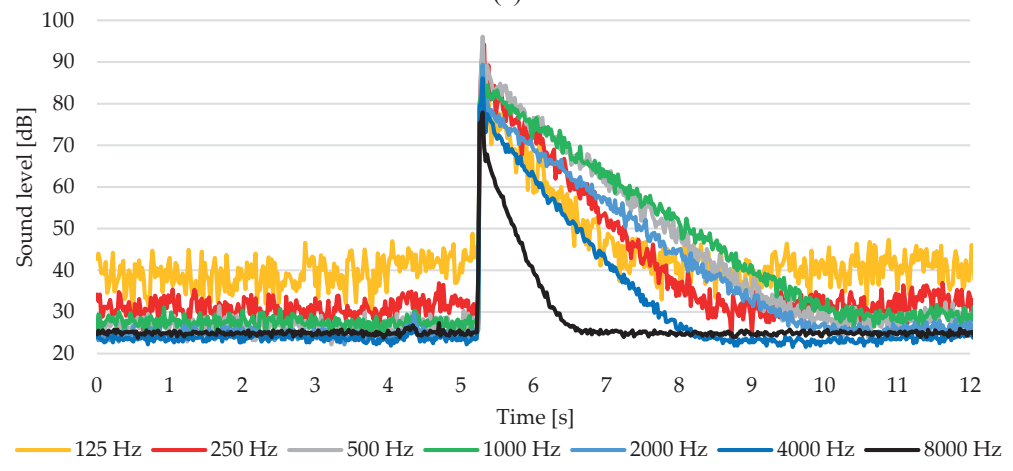

(b)

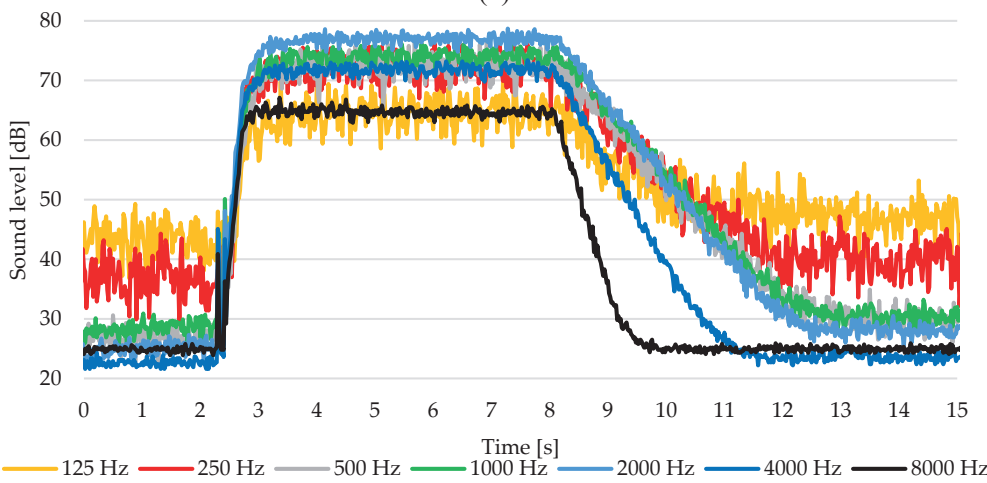

Fig. 9. The graphs of sound levels using the impulse response method (a) and interrupted noise method (b)

Again, the background noise was recorded before and at the end of the test. The peak sound pressure level was obtained in a similar way, and its decrease was similar for both measurement variants. An example of the relationship for point 8 for $4000 \mathrm{~Hz}$ is presented below in Fig. 10.

(a)

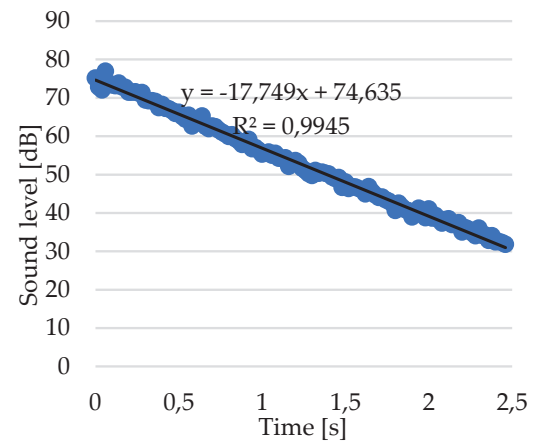

(b)

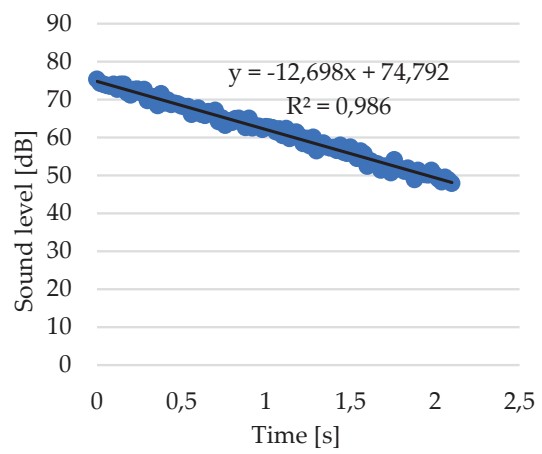

Fig. 10. The graphs of the sound pressure drop for the frequency of $4000 \mathrm{~Hz}$ obtained by the impulse method (a) and interrupted noise method (b) 
Despite the quite good fitting of the trend line to the measurement points and high values of the $\mathrm{R}^{2}$ coefficient, the obtained slope factors of the straight lines differ significantly in both cases. For the balloon test, the sound pressure level drop was faster than for the loudspeaker noise measurement. A significant discrepancy in the directional coefficients of the fadeaway curves results in a significant difference in the obtained reverberation times for point 8 for the analysed measurement variants. Significant differences have been observed for the extreme bands, i.e. 125, 250, 4000 and $8000 \mathrm{~Hz}$. In the case of the highest frequency, this discrepancy does not affect the reverberation time due to the fairly high slope of the trend line. The difference of $10.3 \%$ corresponds to only 0.2 second, which is not very significant with a reverberation time of 1.8 second. For the remaining cases, the differences show higher values. The largest of them is $25 \%$ at $125 \mathrm{~Hz}$.

In order to evaluate the acoustics in the temple, the reverberation time values for the tested frequencies were analysed. It turned out that for the points located on the left side of the chapel and for the source located at point 17, the decrease in sound pressure was slower than for the points on the right side. In point 12, the decrease occurs much faster than for other variants. Despite the illustrated discrepancies, the characteristic of the building is practically constant for each measuring point, regardless of the location of the source and the measurement method used. This is best seen for the $1000 \mathrm{~Hz}$ band, where the difference in the reverberation time is only $1 \%$ for all the measurements made. Based on the data obtained, it can be concluded that the acoustic reception in the temple should be the same for all the members of the congregation gathered in it, and for people in the area of the presbytery.

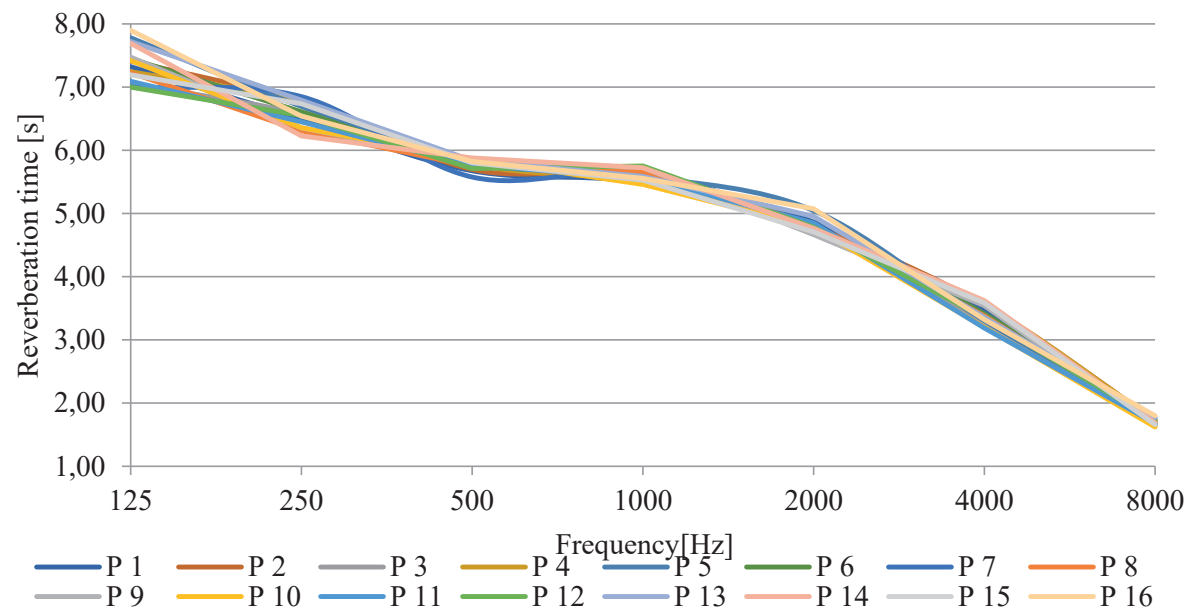

Fig. 11. Reverberation time at various measuring points obtained by the impulse response method

The chart in Fig. 11 shows the dependence of the reverberation time on the frequency for the examined points (an exploding balloon as the sound source). The charts for all measurement points coincide with each other, creating a uniform scheme of the building acoustics. Only for the lowest frequency values, there are differences on the level of $4 \%$. This, as explained previously, is caused by a poorer adjustment of the straight line to the results. For 
the remaining frequencies, the difference in the obtained results is within $1 \%$. Despite these facts, it can be noticed that the interior of the sanctuary largely differs from the interior of the church. In the case of the church, the sounds in the lowest frequency band have the longest reverberation time, up to 8 seconds, while for higher frequency values, the reverberation time decreases. The longest reverberation time for the church occurred in the $1000 \mathrm{~Hz}$ band and it was at the level of approx. 5.5 seconds. The smallest value, approx. 1.8 second, occurred at $8000 \mathrm{~Hz}$, as it was for the chapel, where the reverberation time was approx. 1.5 second. For the obtained chart of the sanctuary profile, the longest reverberation time occurs for the lowest frequencies and decreases with increasing frequency. This is a typical characteristic of interiors that are not adapted. This is due to easier damping of shorter waves and the damping properties of the air itself.

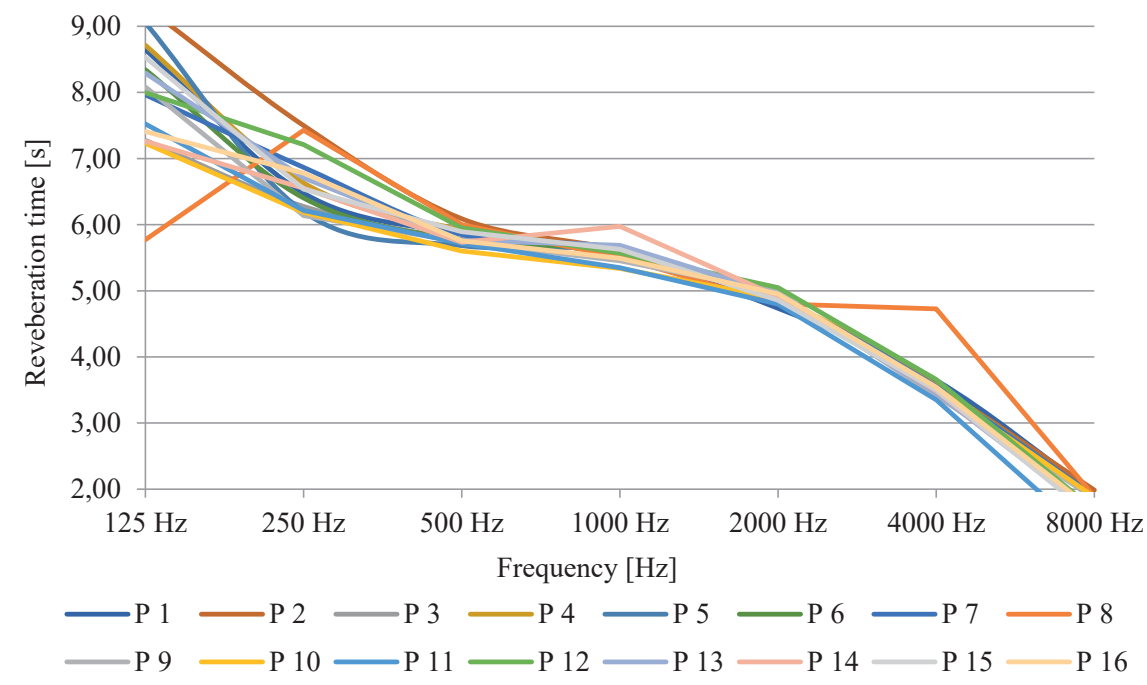

Fig. 12. Reverberation time at various measuring points obtained by the interrupted noise method

The chart of the facility profile was also prepared for the variant with a loudspeaker; it is presented below in Fig. 12. The chart for the variant with the loudspeaker and the source location in the presbytery does not present the uniform character of the interior. One point is most conspicuous here - its character is different from all others, and divergences in the 125 and $250 \mathrm{~Hz}$ bands can be noticed. For the lowest tested frequency, the reverberation time range, depending on the analysed point, is from 7 to 9 seconds, which is a difference of $27.5 \%$. 2 second difference aggravates a listener's acoustic perception and may cause unfavourable acoustic phenomena such as audible reverberation. The discrepancy of the results is also noticeable for 250 and $8000 \mathrm{~Hz}$. However, it is best illustrated by the chart of reverberation time changes in frequency bands (Fig. 13). 


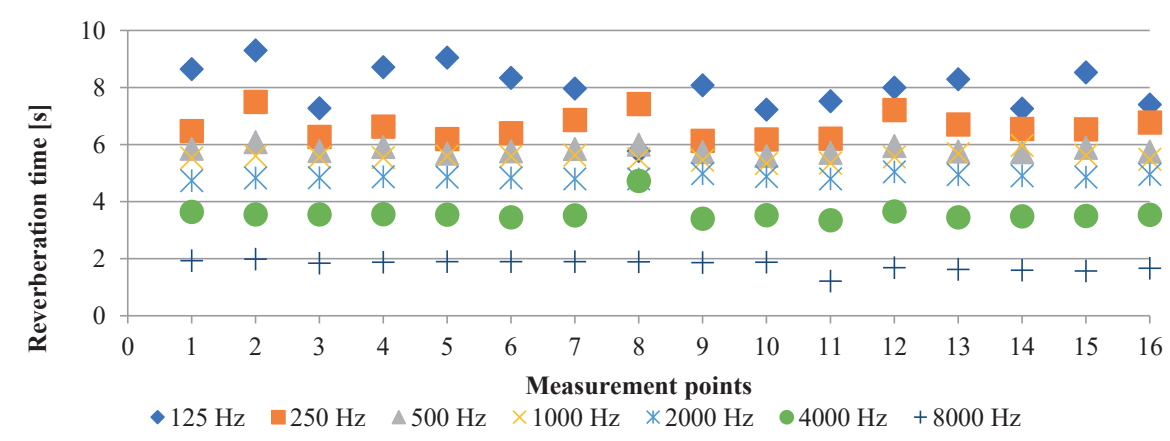

Fig. 13. Reverberation time graph in individual frequency bands at different measuring points

For 500, 1000 and $2000 \mathrm{~Hz}$ bands, the charts are constant with slight ripples. The more wavy the chart of a given frequency, the greater the number of reverberation time spikes at the points of the grid, which entails worsened acoustics of the room and differences in the perception of sounds by the audience. Inside the sanctuary, there are flat surfaces and not much decoration. The sanctuary is finished, but inside there are mostly sound-reflecting surfaces, and the vault is a dome. The floor is made of marble and a large part of the walls is covered with stained glass. These are surfaces that reflect sound well. The temple is crowned with a dome, which does not improve the acoustics of the interior either.

\section{Discussion}

The acoustics of the sanctuary in terms of the reverberation times obtained can be compared with St. Michael's Monastery in Kiev [2]. The volume of both temples is the same, and the acoustic profiles of the buildings are of the same shape. The reverberation time values given in [2] are practically the same as the average values obtained from the sanctuary studies. The discrepancy is only in the highest frequencies.

The problem of acoustics of domed structures intended for religious worship has been discussed previously [18]. The acoustic assessment of the interiors was performed on the basis of reverberation time measurement and the calculation of the speech transmission index. The obtained reverberation time values reached similar values as for the sanctuary. Acoustic conditions were defined as unfavourable for speech audibility and music perception. To adapt the interior to the needs of users, sprayed insulation material was used. After the acoustic adaptation, the reverberation time decreased significantly and the speech clarity improved at all measuring points. It follows that the conditions in the sanctuary are unfavourable. The reverberation time is too long due to the lack of sound-absorbing surfaces. It is necessary to carry out an acoustic adaptation of the interior in order to shorten the reverberation time.

\subsection{Reverberation time}

Tables 1 and 2 show the average reverberation times for the analysed temples in frequency bands. The average values are shown in Fig. 14. 
Table 1. Average reverberation time in the church

\begin{tabular}{llllllll}
\hline \multirow{2}{*}{ Variant } & 125 & 250 & 500 & 1000 & 2000 & 4000 & 8000 \\
& $\mathrm{~Hz}$ & $\mathrm{~Hz}$ & $\mathrm{~Hz}$ & $\mathrm{~Hz}$ & $\mathrm{~Hz}$ & $\mathrm{~Hz}$ & $\mathrm{~Hz}$ \\
\hline K1 balloon & 3.3 & 3.3 & 4.4 & 5.2 & 4.8 & 3.1 & 4.5 \\
\hline K2 balloon & 3.5 & 3.4 & 4.4 & 5.3 & 4.8 & 3.1 & 4.6 \\
\hline K1 speaker & 3.3 & 3.4 & 4.4 & 5.3 & 4.9 & 3.2 & 5.0 \\
\hline K2 speaker & 3.5 & 3.4 & 4.4 & 5.4 & 5.1 & 3.3 & 5.2 \\
\hline Average value & 3.4 & 3.4 & 4.4 & 5.3 & 4.9 & 3.2 & 4.8 \\
\hline
\end{tabular}

Table 2. Average reverberation time in a sanctuary. Source: own study

\begin{tabular}{llllllll}
\hline \multirow{2}{*}{ Variant } & 125 & 250 & 500 & 1000 & 2000 & 4000 & 8000 \\
& $\mathrm{~Hz}$ & $\mathrm{~Hz}$ & $\mathrm{~Hz}$ & $\mathrm{~Hz}$ & $\mathrm{~Hz}$ & $\mathrm{~Hz}$ & $\mathrm{~Hz}$ \\
\hline S1 balloon & 7.4 & 6.6 & 5.8 & 5.6 & 4.8 & 3.4 & 5.7 \\
\hline S1 speaker & 7.9 & 6.6 & 5.8 & 5.6 & 4.9 & 3.6 & 5.4 \\
\hline S2 balloon & 7.5 & 6.6 & 5.8 & 5.6 & 4.9 & 3.4 & 5.7 \\
\hline S2 speaker & 7.9 & 6.7 & 5.8 & 5.6 & 4.9 & 3.6 & 5.7 \\
\hline S3 balloon & 7.5 & 6.6 & 5.8 & 5.6 & 4.9 & 3.3 & 5.7 \\
\hline S3 speaker & 7.7 & 6.7 & 5.9 & 5.6 & 4.9 & 3.6 & 5.7 \\
\hline Average value & 7.7 & 6.6 & 5.8 & 5.6 & 4.9 & 3.5 & 5.6 \\
\hline
\end{tabular}

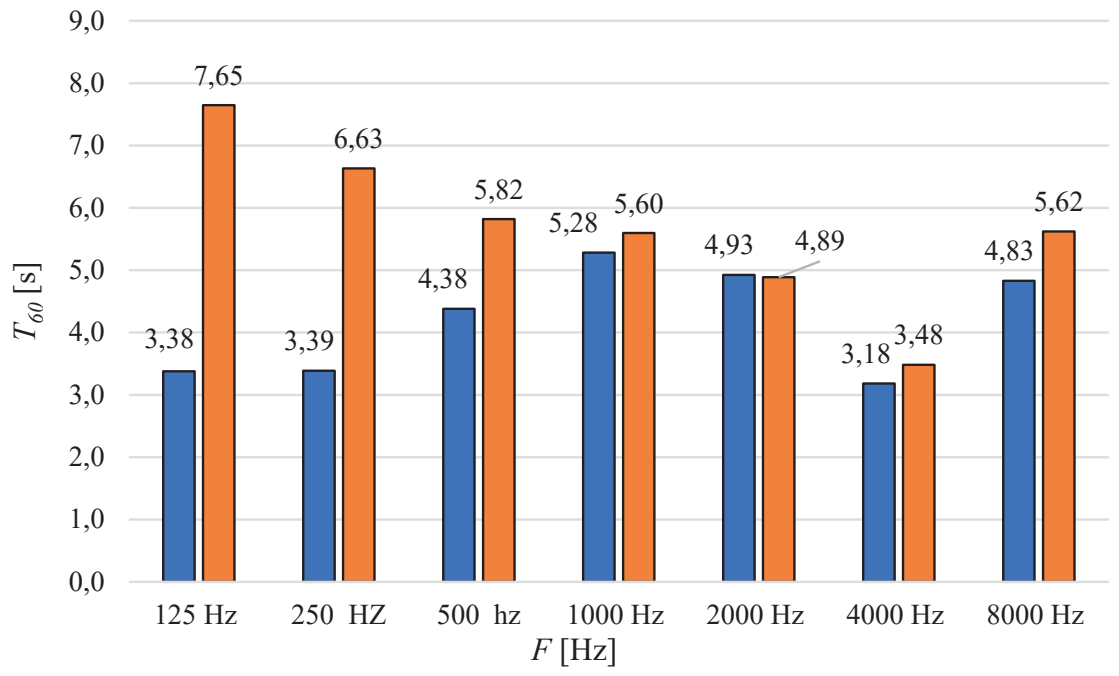

Fig. 14. The average reverberation time in the Church and in the Sanctuary

Comparing of the obtained values for both temples reveals that the average reverberation times for the chapel and the church are comparable for frequencies from 1000 to $8000 \mathrm{~Hz}$. On the other hand, for the lowest frequency bands, the average reverberation time is much longer for the sanctuary and is more than twice as long in the range of $125 \mathrm{~Hz}$ compared to the value obtained in the church. Taking into account the volume of these interiors, which is 2.5-3 times smaller in the sanctuary, the difference in the reverberation time indicates very poor acoustics of this building. For a church, the maximum value of the reverberation time occurs for $1000 \mathrm{~Hz}$ and reaches approx. 5.3 seconds. In the sanctuary, the reverberation 
time decreases with increased sound frequency. The longest reverberation time occurs for $125 \mathrm{~Hz}$ band.

The acoustics of sacred spaces, due to the variety of forms, shapes, geometry, the surface of the building, or church equipment, is not shaped in the same way for every interior. Therefore, there is no standard range of reverberation time values that a temple should meet. Many scientists focused on the topic of the acoustics of sacred objects and, based on their own research, they have created dependencies regarding the optimal reverberation time. Günter Hartman [19] created a model for small and mid-sized churches in terms of the recommended reverberation time range. The volume of the sanctuary is $4681.5 \mathrm{~m}^{3}$, while the volume of the church is $12258.5 \mathrm{~m}^{3}$. Because the volume of the church is only slightly larger than the range for which the Hartman formula applies, the preferred reverberation time was calculated for those temples where $T_{\mathrm{Hk}}$ was the time for the church, and $T_{\mathrm{HS}}$ was the time for the sanctuary.

$$
\begin{aligned}
& T_{H K}=0.0598 \cdot 12258.5^{0.462} \pm 15 \%=(3.94-5.32) \mathrm{s} \\
& T_{H S}=0.0598 \cdot 4681.5^{0.462} \pm 15 \%=(2.52-3.41) \mathrm{s}
\end{aligned}
$$

Average reverberation times for the temples obtained from the conducted research are: $T_{\mathrm{k}}=3.72 \mathrm{~s}$ for the church, $T_{\mathrm{S}}=5.11 \mathrm{~s}$ for the sanctuary. The above dependencies show that the reverberation time for the church is too short, while for the sanctuary it is too long. Klepper [19] divided the temples into four groups and specified the preferred reverberation time values for them. According to this division, both analysed objects belong to the group of mid-sized churches, but neither of them has adequate acoustics according to Klepper's guidelines.

The values recommended by the literature differ. This is because the research relates to historical temples, where the acoustics were shaped along with the next epoch. It is, therefore, difficult to compare the reverberation of a contemporary church to the values recommended in the literature. Variations on other comparative theories and models for predicting energetic acoustic parameters in churches that differ in style, typology and location were discussed in the article [20].

\subsection{Reverberation indicator}

Due to the specific nature of sacred buildings, classic measurement methods for the acoustic assessment of these spaces do not provide a complete acoustic picture of the interior. Work was undertaken to standardize these methods and an index method for assessing the acoustic quality of sacred objects was developed. The method is based on the determination of one global index taking values from 0 to 1 , where 0 means bad and 1 the most favourable reverberation conditions for the interior. This subject is discussed in the papers [2], [21], [22] such as reverberation time (RT. Literature provides a number of partial indices needed to calculate the final value. They include: reverberation index, internal noise index, music sound quality index, speech clarity index and sound uniformity index. To compare the obtained reverberation times with the analysed methods, this paper focuses solely on the reverberation indicator, which is the most important parameter in the index method. On the basis of the above-mentioned works, individual components and the final reverberation indicator for temples were calculated (Table 3). 
Table 3. Reverberation factor for the temples

\begin{tabular}{lllllll}
\hline \multirow{2}{*}{ Temple } & 125 & 250 & 500 & 1000 & 2000 & 4000 \\
& $\mathrm{~Hz}$ & $\mathrm{~Hz}$ & $\mathrm{~Hz}$ & $\mathrm{~Hz}$ & $\mathrm{~Hz}$ & $\mathrm{~Hz}$ \\
\hline The church & 0.6 & 0.7 & 0.5 & 0.6 & 0.6 & 0.8 \\
\hline The sanctuary & 0.1 & 0.1 & 0.3 & 0.4 & 0.5 & 0.6 \\
\hline
\end{tabular}

The obtained values of the indicator for the church were in the range of $0.5-0.8$, with the lowest indicator determined for the $500 \mathrm{~Hz}$ band, and the highest for $4000 \mathrm{~Hz}$. The evaluation of the reverberation indicator can be made according to the scale for the global indicator presented in [2]. Therefore, it can be concluded that there is sufficient acoustic quality for the lower frequencies, while from $1000 \mathrm{~Hz}$ upwards, there is a good acoustic quality of the room in terms of reverberation time, for speech and organ music.

The reverberation indicator values obtained for the sanctuary, as for the church, reach their maximum values for the highest frequencies, but they are much lower. According to the scale presented in [2], poor acoustics of the sacred interior, and in this case, unfavourable reverberation time, occurs for a reverberation indicator of $0-0.6$. This means that only for the frequency of $4000 \mathrm{~Hz}$ acoustic quality of the room is sufficient. Looking globally, the acoustics in the sanctuary is poor and the indicators for speech and the reverberation-volume index predominate. Quality of the interior is much better for organ music and if the reverberation indicator for organ music were considered separately [2], the temple would show good, and even very good acoustic conditions for playing the organ.

\section{Conclusions}

Churches have a variety of forms. They differ not only in shape, but also in the degree of interior development, depending on when the temple was built, and on the type of acoustic purpose, i.e. speech, singing, music. Depending on the religious denomination, different aspects are emphasized. All these features significantly affect the acoustic character of a sacred building.

In this paper, acoustic tests were carried out for two sacred buildings with different volume and shapes. The conducted analyses showed that the applied methods are consistent with each other and the results are comparable. Both for the chapel and for the church, the greatest discrepancies in the obtained reverberation times occurred for the $125 \mathrm{~Hz}$ band. This dependence is caused by a worse - in relation to other frequencies - adjustment of the trend line to the scattergram of the recorded sound pressure drop. The recorded values of the pressure level decreased abruptly with significant differences in subsequent time intervals. For the remaining frequencies this decrease was linear, which allowed for better matching of the lines to the obtained charts. Significant discrepancies in the reverberation time for individual measurement variants were observed in the case of the church for the frequencies of 500 and $2000 \mathrm{~Hz}$, while in the case of the chapel, for frequencies of 250,4000 and $8000 \mathrm{~Hz}$. The highest convergence of test results in all variants was obtained for the frequency of $1000 \mathrm{~Hz}$. Human hearing is most precise in the frequency range from $1000 \mathrm{~Hz}$ to $3000 \mathrm{~Hz}$, so the obtained reverberation time values at the same level for different locations of the sound source and with the use of different sound generators prove the same acoustic perception in the whole room.

The analysis of the reverberation indicator shows that the average indicator for the church is 0.6 , which corresponds to sufficient acoustics, and for the sanctuary, it is 0.3 , which means poor acoustics. When analysing the components of the reverberation indicator, it was noticed 
that poor acoustics in the sanctuary concerns speech, while interior acoustics is good for the reception of organ music.

In the church, the reception of liturgical music is also better than the reception of speech, but the differences between these values are small. The research carried out in this paper establishes the basis for further analysis of how to improve the acoustics in the studied temples. This analysis should be based on proposing systems allowing to improve the conditions of speech, singing and music perception. For a church, it may be a suitable interior finish with sound-absorbing materials. In the sanctuary, however, due to the very long reverberation time in the low frequency range, it will be necessary to use additional sound-absorbing systems.

\section{Funding:}

This work was carried out as a part of the projectUPB-DZS-51 Tab-032-3126-01/18 supported by West Pomeranian University of Technology, Szczecin, Poland.

\section{References}

[1] Kulowski A., Akustyka Sal.Zalecenia Projektowe Dla Architektów. Gańsk: Wydawnictwo Politechniki Gdańskiej, 2011; ISBN 978-83-7348-364-4.

[2] Engel Z. et al., Podstawy Akustyki Obiektów Sakralnych. Kraków-Radom: ITE-PIB, 2007, ISBN 978-83-7204-622-2.

[3] Martellotta F. et al., "Guidelines for Acoustical Measurements in Churches DAU”, Applied Acoustics, vol. 70, 2009, pp. 378-388. https://doi.org/10.1016/j.apacoust.2008.04.004

[4] Girón S., Álvarez-Morales L., Zamarreño T., "Church Acoustics: A State-of-the-Art Review after Several Decades of Research", Journal of Sound and Vibration, vol. 411, 2017, pp. 378-408. https://doi.org/10.1016/j.jsv.2017.09.015

[5] Carbonari A. et al., "Measuring Methods for the Acoustical Characterization of Churches", in International congress on acoustics Madrid, 2007.

[6] Carvalho A.P.O., "Objective Acoustical Analysis of Room Acoustic Measurements in Portuguese Catholic Churches", in Proceedings Noise-Con 94, Ft. Lauderdale, Florida, 1994.

[7] Carvalho A.P.O., Silva, P.M.A., "Sound, Noise and Speech at the 9000-Seat Holy Trinity Church in Fatima, Portugal", Archives of Acoustics, vol. 35, 2010, pp. 145-156.

[8] Plewa M., "Analysis of Sound Field in Dominicans' Church in Cracow”, Archives of Acoustics, vol. 32, 2007, pp. 227-233.

[9] Małecki P., Wiciak J., Nowak D., "Acoustics of the Orthodox Churches in Poland", Archives of Acoustics, vol. 42, 2017, pp. 559-590. https://doi.org/10.1515/aoa-2017-0062

[10] Sygulska A., "The Study of the Influence of the Ceiling Structure on Acoustics in Contemporary Churches", Archives of Acoustics, vol. 44, 2019, pp. 169-184. https://doi.org/10.24425/ aoa.2019.126363

[11] Tronchin L., Bevilacqua A., "Evaluation of Acoustic Similarities in Two Italian Churches Honored to S. Dominic", Applied Sciences, vol. 10, 2020, 7043. https://doi.org/10.3390/app10207043

[12] Merli F., Bevilacqua A., "Using a Church as a Temporary Auditorium. Acoustical Design of S. Domenico of Imola", J. Phys.: Conf. Ser., vol. 1655, 2020, 012146. https://doi.org/10.108 8/1742-6596/1655/1/012146

[13] PN-EN ISO 3382 - 2:2008 + AC:2009: Acoustics - Measurement of Room Acoustic Parameters - Part 2: Reverberation Time in Ordinary Rooms.

[14] Galindo M., Zamarreno T., Giron S., "Acoustic Analysis in Mudejar-Gothic Churches: Experimental Results”, J. Acoust. Soc. Am., vol. 117, 2005, pp. 2873-2888. 
[15] Kandybowicz A., Acoustic Research and Analysis of Selected Sacred Objects in Szczecin. Master thesis, West Pomeranian University of Technology, Szczecin, Poland. 2020.

[16] Álvarez-Morales L. et al., "Methodology for the Study of the Acoustic Environment of Catholic Cathedrals: Application to the Cathedral of Malaga", Building and Environment, vol. 72, 2014, pp. 102-115. https://doi.org/10.1016/j.buildenv.2013.10.015

[17] Szłapa P. et al., "Comparison of Handgun Shots, Balloon Bursts, and a Compressor Nozzle Hiss as Sound Sources for Reverberation Time Assessment", Archives of Acoustics, vol. 41, 2016, pp. 683-690. https://doi.org/10.1515/aoa-2016-0065

[18] Nowoświat A., Marcelina O., Marchacz M., "The effect of acoustical remedies changing the reverberation time for different frequencies in a dome used for worship: A case study", Applied Acoustics, vol. 160, 2020, 107143. https://doi.org/10.1016/j.apacoust.2019.107143

[19] Wróblewska D., Kulowski A., Czynnik akustyki w architektonicznym projektowaniu kościołów. Gdańsk: Wydawnictwo Politechniki Gdańskiej, 2007.

[20] Berardi U., Cirillo, E., Martellotta F.A., "Comparative Analysis of Acoustic Energy Models for Churches", J Acoust Soc Am, vol. 126, 2009, pp. 1838-1849. https://doi.org/10.1121/1.3205398

[21] Kosała K., Engel Z., "Assessing the Acoustic Properties of Roman Catholic Churches: A New Approach", Applied Acoustics, vol. 74, 2013, pp. 1144-1152. http://doi.org/10.1016/j. apacoust.2013.03.013

[22] Kosała K., "A Single Number Index to Assess Selected Acoustic Parameters in Churches with Redundant Information", Archives of Acoustics, vol. 36, 2011, pp. 545-560. https://doi.org/10.2478/ v10168-011-0039-3 
